\title{
Isolation and Properties of Auxotrophic Mutants of Mycobacterium smegmatis Requiring either Salicylic Acid or Mycobactin
}

\author{
By C. RATLEDGE AND M. J. HALL \\ Department of Biochemistry, The University of Hull, \\ Kingston upon Hull, Yorkshire, HU6 7 RX
}

(Accepted for publication 23 March 1972)

\begin{abstract}
S UMMAR Y
A mutant of Mycobacterium smegmatis required 3 to $4 \mu \mathrm{g}$ salicylate, or certain other phenolic acids/ml to restore optimal growth. Iron-deficient growth did not increase the requirement for salicylate. Salicylate, but not a salicylate-substitute was incorporated solely into mycobactin S. Mycobactin S was absorbed by growing bacteria but it did not substitute or spare the requirement for salicylate. Another mutant has been produced which required about $0.2 \mu \mathrm{g}$ desferrimycobactin $\mathrm{S} / \mathrm{ml}$ to restore growth under iron-deficient conditions. Salicylate, citrate, cobactin $S$ with mycobactic acid $S$ or Tween 80 did not substitute for mycobactin, but iron at 2 or more $\mu \mathrm{g} / \mathrm{ml}$ permitted growth without mycobactin. Under these growth conditions the mycobactin requirement would be minute and some synthesis or carry-over during inoculation cannot be eliminated as a source of mycobactin. Salicylate and mycobactin were thus both required for growth.
\end{abstract}

\section{INTRODUCTION}

Mycobacteria produce two ferric ion binding compounds: mycobactin, which is lipophilic, located intracellularly and of molecular weight about 850 (Snow, 1970), and salicylic acid (or, in some species, 6-methylsalicylic acid) which is water-soluble and occurs only extracellularly (Ratledge \& Winder, 1962, 1966). The formation of both compounds increases under iron-deficient growth conditions, indicating a possible control of biosynthesis by iron (Antoine \& Morrison, 1968; Hudson \& Bentley, 1970; Ratledge \& Hall, I971; Marshall \& Ratledge, 1972). Salicylate, however, is partly taken up from the medium by Mycobacterium smegmatis and used in the synthesis of mycobactin S (Ratledge \& Hall, 1970). Its accumulation in iron-deficient cultures, therefore, may not be for a specific function but could be due to the over-production of a mycobactin presursor (Snow, 1970). The role of mycobactin is clearer: in iron-deficient $M$. smegmatis it acts as a carrier, or ionophore, for the transport of ferric ions across the lipid boundary layers of the mycobacterial cell (Ratledge, 197I; Ratledge \& Marshall, 1972).

We have attempted to resolve whether both ferric ion binding compounds are needed for the development of the organism by producing auxotrophs of Mycobacterium smegmatis requiring each compound separately and determining if either compound can satisfy the requirement for the other.

\section{METHODS}

Organisms and growth. Two strains of Mycobacterium smegmatis were used: NCIB 8548 and one of unknown origin (see Ratledge \& Winder, 1962) referred to as the DUBLIN strain. They 
were grown at $37{ }^{\circ} \mathrm{C}$ on minimal medium freed of trace metal ions as previously described (Ratledge \& Hall, I97I) and supplemented with $(\mu \mathrm{g} / \mathrm{ml}) \mathrm{Zn}^{2+}, 0.46 ; \mathrm{Mn}^{2+}, 0 . \mathrm{I} ; \mathrm{Mg}^{2+}, 40$; and $\mathrm{Fe}^{2+} 0.05$ or $0 . \mathrm{I}$ for iron-deficient growth, or 2.0 for iron-sufficient growth. Cultures were grown in $100 \mathrm{ml}$ of liquid media contained in $250 \mathrm{ml}$ conical flasks which were stationary or shaken orbitally at $250 \mathrm{rev} . / \mathrm{min}$. Bacterial dry weights were determined as previously described (Ratledge \& Hall, 197I).

Mutagenesis and selection of auxotrophs. The isolation of a salicylate requiring auxotroph of Mycobacterium smegmatis DUBLIN has been reported (Holland \& Ratledge, 1971). For the isolation of a mycobactin auxotroph modifications to this technique were necessary. Tween 80 previously used at I \% to disaggregate clumps of bacteria, partially extracted mycobactin from bacteria (unpublished work) thus causing unwanted cross-feeding and was therefore omitted, except from solid medium where it was used at $0.1 \%$. The liquid medium used was always iron-deficient. No period for phenotypic expression was allowed after treatment with mutagen ( $N$-methyl- $N$-nitro- $N$-nitrosoguanidine at $250 \mu \mathrm{g} / \mathrm{ml}$ for $60 \mathrm{~min}$ ). Isoniazid was replaced by 4 -aminosalicylate $(\mathrm{r} \mathrm{mg} / \mathrm{ml})$ for auxotroph selection from the population of mixed mutants, as isoniazid, by inhibiting mycolic acid biosynthesis (Winder \& Collins, 1970) might disrupt the bacterial walls which contain these acids and release mycobactin into the medium. Following auxotroph selection, cultures were grown on liquid medium containing I $\mu \mathrm{g}$ ferrimycobactin S/ml for $24 \mathrm{~h}$ then plated out on solid medium (20 ml per Petri dish) on to which $25 \mu \mathrm{g}$ ferrimycobactin S in $0.2 \mathrm{ml}$ ethanol had previously been spread. Before inoculation the ethanol was allowed to evaporate by holding the Petri dish in an inverted position at $37^{\circ} \mathrm{C}$ for $30 \mathrm{~min}$.

The concentrations of growth factors (amino acids, vitamins, purines and pyrimidines) and techniques of replica plating, serial dilution, etc. were as previously described (Holland \& Ratledge, 1971).

Determination, extraction and hydrolysis of mycobactin. Mycobactin S was extracted and assayed as described by White \& Snow (1968, I969). The limit of sensitivity of the spectrophotometric method of assay is about $60 \mu \mathrm{g}$ of ferrimycobactin. Thin-layer chromatography of ferrimycobactin $S$ was carried out according to White \& Snow (1968) using cyclohexane + 2-methylpropan-2-ol + propane-I, 2-diol (40: 10 : I, by vol.). To estimate ${ }^{14} \mathrm{C}-$ labelled material, areas of the chromatogram were eluted into ethanol and counted by liquid scintillation. For examination of the aromatic moiety, ferrimycobactin was refluxed with $5 \mathrm{M}-\mathrm{HCl}$ for $6 \mathrm{~h}$ and extracted with ether (Ratledge \& Hall, 197I). Spectra of the ether extracts were scanned from $220 \mathrm{~nm}$ to $370 \mathrm{~nm}$ in a Unicam SP800 recording spectrophotometer.

Recovery of $\left[\right.$ carboxy $\left.-{ }^{14} \mathrm{C}\right]$ salicylate from medium. [Carboxy- $\left.{ }^{14} \mathrm{C}\right]$ salicylate, still remaining in the medium after incorporation experiments, was recovered by ether extraction (three times with 0.5 vol. at $\mathbf{p H ~ 2 ) . ~ A s ~ a ~ s m a l l ~ a m o u n t ~ o f ~ r a d i o a c t i v i t y ~ r e m a i n e d ~ u n e x t r a c t e d , ~ t h e ~}$ medium, at pH 6.5, was evaporated and the residue twice extracted into $100 \mathrm{ml}$ chloroform + methanol $(2: \mathrm{I}, \mathrm{v} / \mathrm{v})$; this extract after concentration to a small volume was chromatographed with propan-2-ol + aq $\mathrm{NH}_{3}$ + water (8: I : I, by vol.) on Whatman no. I paper for $\mathrm{I} 6 \mathrm{~h}$ in an ascending direction. The residue which failed to extract into chloroform + methanol was shaken with hot ethanol and a portion also chromatographed in the same solvent system. Each chromatogram was scanned with a windowless scintillation detector (model CS-03, Panax Equipment Ltd, Redhill, Surrey); in each the radioactivity coincided with the mass of salicylate, added as a carrier, which was visualized under u.v. light.

Chemicals. Phenolic acids were recrystallized from water before use. Mycobactin S was extracted from Mycobacterium smegmatis DuBLIN and taken to $99 \%$ purity by a modification of the procedure of White \& Snow (1969). In experiments, ferrimycobactin S was normally 


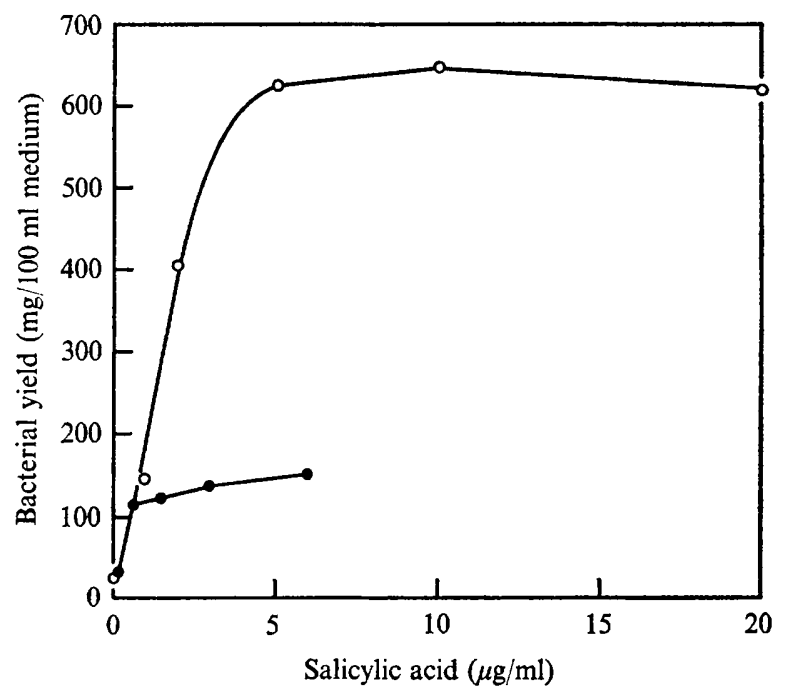

Fig. I. Response of a salicylate auxotroph of Mycobacterium smegmatis $\$ 278$ to salicylic acid. $\mathrm{Fe}^{2+}$ was at $2.0 \mu \mathrm{g} / \mathrm{ml}(\mathrm{O})$ or $0.1 \mu \mathrm{g} / \mathrm{ml}$. (0). Growth was in unshaken liquid medium for 6 days.

used; whenever desferrimycobactin $\mathbf{S}$ was used this is stated explicitly in the text. Desferrimycobactin S was prepared according to Snow (1965). [Carboxy ${ }^{14} \mathrm{C}$-salicyloyl]mycobactin was prepared by growing M. smegmatis DUBLIN on iron-deficient medium with $0.4 \mu \mathrm{g}$ $\left[\right.$ carboxy $\left.{ }^{14} \mathrm{C}\right]$ salicylic acid/ml and extracting and purifying the mycobactin produced (Ratledge \& Hall, 1970). Cobactin S and mycobactin acid S were prepared by alkaline hydrolysis of mycobactin (White \& Snow, 1969). [Carboxy-14 C]salicylic acid was obtained from the Radiochemical Centre, Amersham, Buckinghamshire.

\section{RESULTS AND DISCUSSION}

Salicylate-requiring mutant. Suspected mutants derived from Mycobacterium smegmatis DUBLIN were screened for dependence on salicylic acid at $10 \mu \mathrm{g} / \mathrm{ml}$ in unshaken liquid minimal medium. A single, stable, salicylate-requiring auxotroph, designated s278, was eventually found among about 6000 suspected mutants. This auxotroph grew optimally in iron-sufficient $(2 \cdot 0 \mu \mathrm{g} \mathrm{Fe} / \mathrm{ml})$ and iron-deficient ( $0 \cdot \mathrm{I} \mu \mathrm{g} \mathrm{Fe} / \mathrm{ml})$ medium when salicylic acid was added at about $5 \mu \mathrm{g} / \mathrm{ml}$ and $0.7 \mu \mathrm{g} / \mathrm{ml}$ respectively (Fig. I).

Utilization of salicylate. Mycobacterium smegmatis s278, when grown unshaken for 6 days in $800 \mathrm{ml}$ iron-deficient medium containing $4 \mu \mathrm{g}$ [carboxy $\left.{ }^{14} \mathrm{C}\right]$ salicylate $\left(2.44 \times 10^{4}\right.$ d.p.m. $/ \mu \mathrm{g}) / \mathrm{ml}$, incorporated $21 \%$ of the added radioactivity into the bacteria. All the radioactivity in the bacteria was recovered in the mycobactin fraction (Table $\mathrm{I}$ ). The ${ }^{14} \mathrm{C}$ within the mycobactin was assumed to be in the salicylate moiety (Hudson \& Bentley, 1970; Ratledge \& Hall, 1970). Of the radioactivity in the medium ( $79 \%$ of the added material) all was associated with unchanged salicylic acid (see Table I). As no other metabolite derived from it could be found, salicylate is used solely for mycobactin formation.

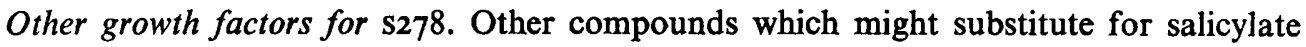
with Mycobacterium smegmatis S278 were tested at $10 \mu \mathrm{g} / \mathrm{ml}$ in minimal medium solidified with agar. After 2 or 3 days of incubation, colony development of \$278 with any of the compounds tested was less than with salicylate. After 4 days, however, growth with 2,3- and 
Table I. Recovery of ${ }^{14} \mathrm{C}$ after growth of Mycobacterium smegmatis \$278 under iron-deficient conditions, in the presence of $\left[\right.$ carboxy-14 C] salicylate $\left(78 \cdot 13 \times 10^{6}\right.$ d.p.m. added $)$

All samples counted by liquid scintillation techniques.

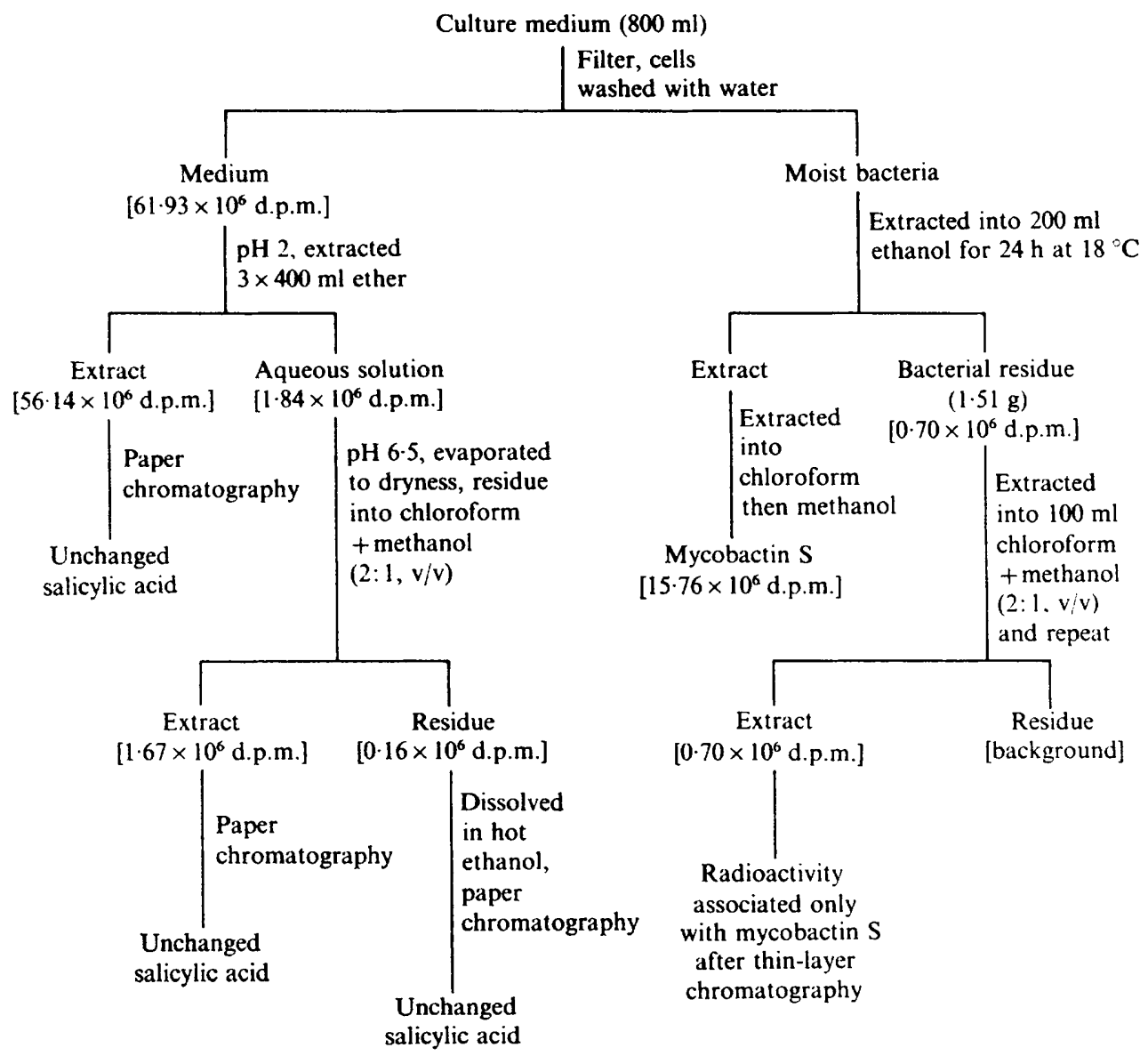

2,4-dihydroxybenzoates equalled that with salicylate. Less growth occurred with 4-aminosalicylate, 2,5-dihydroxybenzoate and 6-methylsalicylate as growth supplements. No growth occurred with L-phenylalanine, L-tyrosine, L-tryptophan, shikimate, hippurate, 4-hydroxybenzoate, 4-aminobenzoate, 2,6-, 3,4- and 3,5-di- or 3,4,5-trihydroxybenzoates. Citrate at 10,100 and $1000 \mu \mathrm{g} / \mathrm{ml}, \mathrm{Fe}^{2+}$ at 5,10 and $20 \mu \mathrm{g} / \mathrm{ml}$, and $100 \mu \mathrm{g}$ citrate $/ \mathrm{ml}$ together with $5 \mu \mathrm{g} \mathrm{Fe}^{2+} / \mathrm{ml}$ also did not substitute for salicylate in solid medium. This mutant thus differs from those of Escherichia coli which cannot synthesize 2,3-dihydroxybenzoate but to which either citrate of $\mathrm{Fe}^{2+}$ can restore growth (Young, Langman, Luke \& Gibson, 197I).

The nature of the aromatic moiety was examined in the mycobactins produced by the mutant grown for 6 days in iron-deficient medium supplemented with 2,3- or 2,4-dihydroxybenzoate or 4 -aminosalicylate each at $5 \mu \mathrm{g} / \mathrm{ml}$. After acid hydrolysis of each mycobactin, only salicylic acid was recovered. As a dehydroxylation of either phenolic acid to salicylate would be an unprecedented biochemical reaction and as radioactivity from 4-amino- 


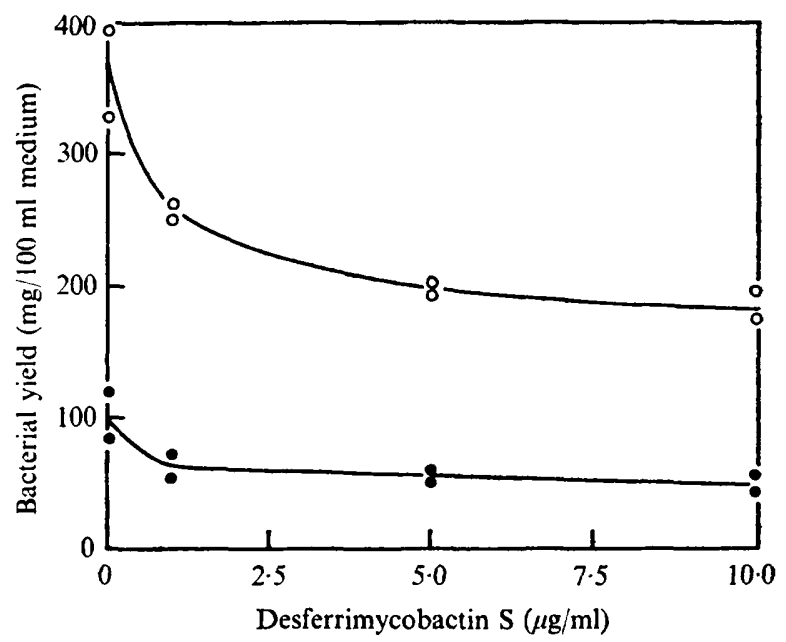

Fig. 2. Effect of desferrimycobactin S on Mycobacterium smegmatis $\$ 278$ growing with $2 \cdot 0 \mu \mathrm{g}$ $\mathrm{Fe}^{2+} / \mathrm{ml}(\mathrm{O})$ or with $0.1 \mu \mathrm{g} \mathrm{Fe}{ }^{2+} / \mathrm{ml}(O)$ in the presence of suboptimal concentrations of salicylate: $1.0 \mu \mathrm{g} / \mathrm{ml}$ and $0.2 \mu \mathrm{g} / \mathrm{ml}$, respectively. Growth was in unshaken liquid medium for 6 days.

[carboxy-14 C]salicylate is not incorporated into the mycobactin (Ratledge \& Brown, 1972) we conclude that these other growth factors were not degraded to salicylate to exert their growth promoting effects. However, the salicylate produced by the mutant is accounted for by the nature of its metabolic defect which does permit some synthesis of salicylate from chorismate via isochorismate, though more slowly than in the wild-type parent organism (Marshall \& Ratledge, 1972).

As mycobactin is the sole product derived from salicylate, its ability to substitute for, or spare the requirement of, salicylate was carefully examined. In solidified minimal medium, mycobactin $S$ and its cleavage products, cobactin $S$ and mycobactin acid $S$, each at $10 \mu \mathrm{g} / \mathrm{ml}$, were ineffective as growth factors for the mutant. In either iron-deficient or iron-sufficient liquid medium, mycobactin $\mathrm{S}$, at $\mathrm{I}, 2,5$ or $10 \mu \mathrm{g} / \mathrm{ml}$, again was ineffective. Addition of desferrimycobactin $S$ (used instead of ferrimycobactin $S$ to prevent possible promotion of growth by ferric ions) to cultures growing with limiting amounts of salicylate under irondeficient or iron-sufficient conditions did not spare the requirement for salicylate (Fig. 2). Some inhibition of growth by desferrimycobactin S, particularly under iron-sufficient growth conditions, was noted. This has been observed before with desferrimycobactin $\mathbf{M}$ and Mycobacterium tuberculosis (Snow \& White, 1969).

The failure of mycobactin $S$ to substitute for salicylate can be explained in one of three ways:

(i) The added mycobactin was rapidly degraded. This is most unlikely as $98 \%$ of [carboxy${ }^{14} \mathrm{C}$-salicyloyl]mycobactin S when added at $2 \mu \mathrm{g} / \mathrm{ml}$ to an iron-deficient culture of $M y c o-$ bacterium smegmatis DUBLIN was taken up from the medium during 6 days of growth and recovered from the mycobactin fraction. If degradation had occurred, most of the radioactivity would have been recovered from the medium as salicylic acid.

(ii) Mycobactin did not permeate into the bacteria. The principal evidence in favour of mycobactin $S$ being actively taken up by the organism is the ability of mutant MI9 (see below), which does not synthesize mycobactin, to grow only if mycobactin is included in the medium. Corroboration that mycobactin can be taken up from the medium to fulfil an essential intracellular role comes from Mycobacterium paratuberculosis and the wood pigeon 


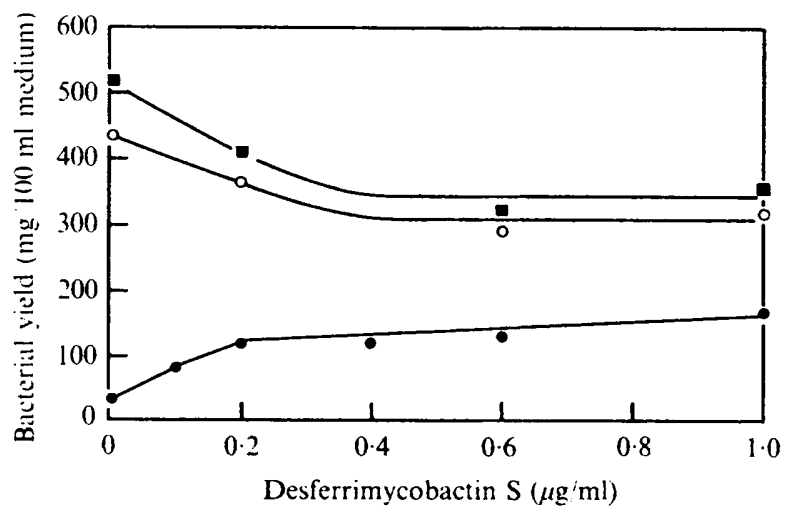

Fig. 3. Response of a mycobactin auxotroph of Mycobacterium smegmatis MI9 to desferrimycobactin S. Iron was at $5.0 \mu \mathrm{g} / \mathrm{ml}(\mathbf{G}), 2.0 \mu \mathrm{g} / \mathrm{ml}(O)$ or $0.1 \mu \mathrm{g} / \mathrm{ml}(\Theta)$. Growth was in shaken liquid medium for 4 days.

mycobacterium, both of which depend on mycobactin for cultivation in vitro (Francis, Macturk, Madinaveitia \& Snow, 1953; Wheeler \& Hanks, 1965).

(iii) Salicylate fulfils a second function besides that of a precursor of mycobactin. This it must do without degradation as no other metabolic product of it has been found. Such a function could be that of an extracellular iron chelator serving to solubilize ferric ions and make them accessible to the organism. The ability of some of the other phenolic acids, which also chelate with ferric ions to promote growth of $\$ 278$ supports this hypothesis.

Mycobactin-requiring mutant. Mycobacterium smegmatis NCIB 8548 was used as parent strain as it contains a higher concentration of mycobactin than $M$. smegmatis DUBLIN (Ratledge \& Hall, 197I) and may, therefore, require more mycobactin. We have found little, if any, significant physiological or metabolic difference between these two strains.

A mycobactin-requiring mutant, designated MI9, was isolated (see Methods) from about 3000 replicated colonies. It grew only very slowly without mycobactin. In liquid irondeficient minimal medium, growth yield was near maximum with $0.2 \mu \mathrm{g}$ or more desferrimycobactin S/ml (Fig. 3) but salicylate $(50 \mu \mathrm{g} / \mathrm{ml})$, citrate $(500 \mu \mathrm{g} / \mathrm{ml})$, cobactin S with mycobactic acid S (each at $0.5 \mu \mathrm{g} / \mathrm{ml}$ ) or $0 . \mathrm{I} \%$ Tween 80 failed to substitute. With high concentrations of iron (2 or $5 \mu \mathrm{g} \mathrm{Fe}{ }^{2+} / \mathrm{ml}$ ), growth occurred without mycobactin (Fig. 3), addition of which reduced the growth yield.

In iron-deficient medium Mycobacterium smegmatis produces $40 \mu \mathrm{g}$ desferrimycobactin $\mathrm{S} / \mathrm{mg}$ dry wt whereas mutant MI 9 is satisfied with $0.2 \mu \mathrm{g} / \mathrm{ml}$, i.e. $0 \cdot 16 \mu \mathrm{g} / \mathrm{mg}$ dry wt. It appears that the production of mycobactin may be 250 times as much as is needed. In iron-sufficient conditions, $M$. smegmatis contains only $2.5 \mathrm{ng}$ mycobactin/ml (Ratledge \& Marshall, 1972); while this may be equal to the required amount it could again be 250 times as much. In the former case M19, yielding $5 \mathrm{mg}$ dry wt $/ \mathrm{ml}$, would need $12.5 \mathrm{ng}$ mycobactin $/ \mathrm{ml}$; in the latter case the need would be for only $50 \mathrm{pg} / \mathrm{ml}$, an amount so small that it may be either synthesized by the mutant or carried over during inoculation. This could account for the growth of the mutant without'mycobactin in iron-sufficient conditions.

Only about $50 \mu \mathrm{g}$ mycobactin, half of the $100 \mu \mathrm{g}$ added to the culture flask, was extracted from M19 grown shaken for 6 days in $100 \mathrm{ml}$ minimal iron-deficient medium. Since the parent strain grown under similar conditions produced about $6 \mathrm{mg}$ mycobactin/flask we conclude that this mutant has probably lost most of its ability to synthesize mycobactin. 
From the characteristics of these mutants we conclude that both mycobactin and salicylate are necessary for the growth of Mycobacterium smegmatis under iron-deficient conditions at least. Such conditions probably exist in animal tissues for mycobacteria (Hanks, I966) and most other bacteria (Weinberg, 1966; Bullen \& Rogers, 1969) although the iron-binding compounds which other bacteria produce are different to those produced by mycobacteria (see Neilands, 1967; Ratledge \& Chaudhry, 197I).

The Wellcome Trust is thanked for its grants in support of this work.

\section{REFERENCES}

ANTOINE, A. D. \& MoRrison, N. E. (I968). Effect of iron nutrition on the bound hydroxylamine content of Mycobacterium phlei. Journal of Bacteriology 95, 245-246.

Bullen, J. J. \& Rogers, H. J. (1969). Bacterial iron metabolism and immunity to Pasteurella septica and Escherichia coli. Nature, London 224, 380-382.

Francis, J., Macturk, H. M., Madinaveitia, J. \& Snow, G. A. (1953). Mycobactin, a growth factor for Mycobacterium johnei. Isolation from Mycobacterium phlei. Biochemical Journal 55, 596-607.

Hanks, J. H. (1966). Host-dependent microbes. Bacteriological Reviews, 30, 11 4-135.

Holland, K. T. \& RATLEDGE, C. (I97I). A procedure for selecting and isolating specific auxotrophic mutants of Mycobacterium smegmatis. Journal of General Microbiology 66, $115-118$.

Hudson, A. T. \& BeNTLEY, R. (1970). Utilization of shikimic acid for the formation of mycobactin S and salicylic acid by Mycobacterium smegmatis. Biochemistry 9, 3984-3987.

Marshall, B. J. \& Ratledge, C. (1972). Salicylic acid biosynthesis and its control in Mycobacterium smegmatis. Biochimica et biophysica acta 264, I06-1 16.

NeILANDS, J. B. (1967). Hydroxamic acids in nature. Science, New York 156, 1443-1447.

RATLEDGE, C. (1971). Transport of iron by mycobactin in Mycobacterium smegmatis. Biochemical and Biophysical Research Communications 45, 856-862.

RATLEDGe, C. \& Brown, K. (1972). Inhibition of mycobactin formation in Mycobacterium smegmatis by $p$-aminosalicylate (PAS). A new proposal for the mode of action of PAS. American Review of Respiratory Disease. (in the press).

Ratledge, C. \& ChaUdhry, M. A. (1971). Accumulation of iron binding phenolic acids by actinomycetales and other organisms related to the mycobacteria. Journal of General Microbiology 66, 7I-78.

RATLEDGE, C. \& HALL, M. J. (1970). Uptake of salicylic acid into mycobactin S by growing cells of Mycobacterium smegmatis. Federation of European Biochemical Societies Letters ro, 309-312.

RATLEDGe, C. \& HALL, M. J. (197I). Influence of metal ions on the formation of mycobactin and salicylic acid in Mycobacterium smegmatis grown in static culture. Journal of Bacteriology 108, 314-319.

RATLEDGE, C. \& MARShall, B. J. (1972). Iron transport in Mycobacterium smegmatis: the role of mycobactin. Biochimica et biophysica acta (in the press).

RATLEDGE, C. \& WINDER, F. G. (1962). The accumulation of salicylic acid by mycobacteria during growth on an iron deficient medium. Biochemical Journal 84, 50I-506.

RATLEDGE, C. \& Winder, F. G. (1966). Biosynthesis and utilization of aromatic compounds by Mycobacterium smegmatis with particular reference to the origin of salicylic acid. Biochemical Journal ror, 274-283.

SNow, G. A. (1965). Isolation and structure of mycobactin T, a growth factor from Myobacterium tuberculosis. Biochemical Journal 97, 166-175.

SNow, G. A. (1970). Mycobactins: iron-chelating growth factors from mycobacteria. Bacteriological Reviews 34, 99-125.

SNow, G. A. \& White, A. J. (1969). Chemical and biological properties of mycobactins isolated from various mycobacteria. Biochemical Journal I15, I03I-I045.

WeINBERG, E. D. (1966). Roles of metallic ions in host-parasite interactions. Bacteriological Reviews 30, I36-I5I.

WHEELER, W. C. \& HANKs, J. H. (1965). Utilization of external factors by intracellular microbes: Mycobacterium paratuberculosis and wood pigeon mycobacteria. Journal of Bacteriology 89, 889-896.

White, A. J. \& SNow, G. A. (1968). Methods for the separation and identification of mycobactins from various species of mycobacteria. Biochemical Journal ro8, 593-597. 
Whire, A. J. \& SNOW, G. A. (1969). Isolation of mycobactins from various mycobacteria. The properties of mycobactins S and H. Biochemical Journal IIr, 785-792.

WINDRR, F. G. \& CollINS, P. B. (1970). Inhibition by isoniazid of synthesis of mycolic acids in Mycobacterium tuberculosis. Journal of General Microbiology 63, 41-48.

Young, I. G., Langman, L., LuKe, R. K. J. \& GrBson, F. (1971). Biosynthesis of the iron-transport compound enterochelin: mutants of Escherichia coli unable to synthesize 2,3-dihydroxybenzoate. Journal of Bacteriology 106, $51-57$. 